\title{
Machine treatment of adult respiratory distress syndrome: Rinse or wash cycle?
}

\author{
Jonathan C. Yeung, MD, PhD, FRCSC
}

\author{
From the Division of Thoracic Surgery, Department of Surgery, University of Toronto, Toronto, Ontario, Canada. \\ Disclosures: Author has nothing to disclose with regard to commercial support. \\ Received for publication Sept 16, 2017; accepted for publication Sept 22, 2017; available ahead of print Oct 25, \\ 2017. \\ Address for reprints: Jonathan C. Yeung, MD, PhD, FRCSC, 200 Elizabeth St, 9N-983, Toronto General Hospital, \\ Toronto, Ontario, Canada M5G 2C4 (E-mail: jonathan.yeung@uhn.ca). \\ J Thorac Cardiovasc Surg 2018;155:449-50 \\ 0022-5223/\$36.00 \\ Copyright $(2017$ by The American Association for Thoracic Surgery \\ https://doi.org/10.1016/j.jtcvs.2017.09.104
}

In this issue of the Journal, Mahaffey and colleagues ${ }^{1}$ describe the use of in vivo lung perfusion (IVLP) for the treatment of sepsis-induced acute lung injury. There is no doubt that acute lung injury and the resulting acute respiratory distress syndrome (ARDS) represent a formidable problem in medicine. Few, if any, highly effective options are available for ARDS. Novel approaches, such as that proposed by Mahaffey and colleagues, ${ }^{1}$ are desperately needed.

The concept of machine perfusion of lungs is not a new one, but implementation of this concept with a stable noninjurious perfusion strategy has only recently been developed., ${ }^{2,3}$ For ex vivo lung perfusion, acellular Steen solution combined with a centrifugal pump, a lowered perfusion flow, and a positive atrial pressure $(3-5 \mathrm{~mm} \mathrm{Hg})$ were found to be key elements for the stable perfusion of human and porcine lungs for 12 hours. ${ }^{4}$ Adherence to these principles has allowed Mahaffey and colleagues, ${ }^{1}$ and others, to recreate stable perfusion of lungs in vivo. ${ }^{5}$ This is an important first step.

Instillation of lipopolysaccharide into the circulation for 2 hours provided a simple yet reproducible injury model, and central venoarterial extracorporeal membrane oxygenation provided the hemodynamic stability from which in vivo lung perfusion of the left lung could be started. Clearly, this is a difficult and expensive surgical model, but we should not let its complexity detract from its clinical applicability. This model uniquely allows the study of isolated organ biology during systemic inflammation. Clinical translation will undoubtedly be more elegant.

Indeed, lungs subjected to this IVLP model had attenuated levels of proinflammatory cytokine production, vascular adhesion molecules, microvascular leakage, and histologic markers of injury. This is reminiscent of the use of ex vivo lung perfusion to attenuate another kind of injury, vector-associated lung injury during gene therapy. ${ }^{6}$ Ex vivo lung perfusion interleukin 10 gene therapy was designed so that interleukin 10 upregulation during ex vivo lung perfusion the lung. the lung?

\section{References} plant. 2008;27:1319-25.

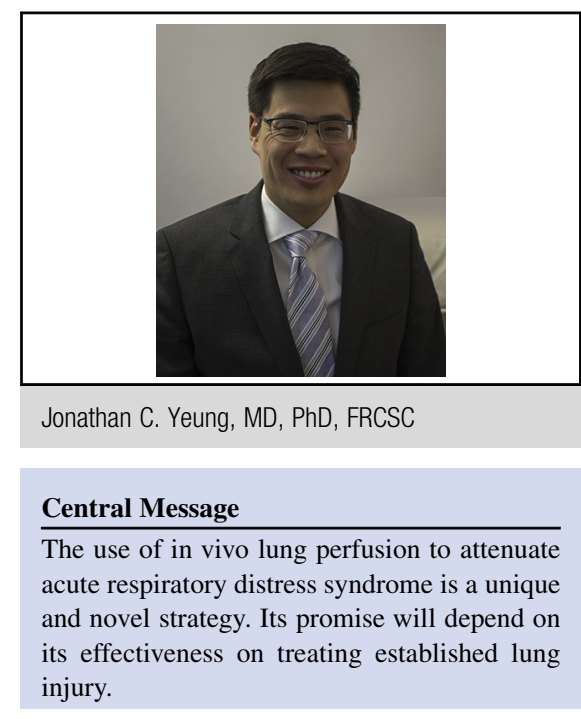

See Article page 440.

would limit vector-induced inflammation to a short period after transplant. In this model, the inflammatory injury is similarly short; lipopolysaccharide has only been circulating for 2 hours before the isolation of

ARDS, in contrast, is a lung injury with established disruption of the air-liquid barrier and alveolar damage. ${ }^{7}$ Consequently, is the benefit seen with IVLP therapy here simply from the rinsing out of LPS and circulating inflammatory cells from the vasculature preventing further injury, or is it actually from washing out established inflammation and healing microvascular injury of

With this model, Dr Kron's group has the exciting opportunity to study and answer this question. Improved understanding of the role of IVLP in ARDS will drive the development of IVLP-delivered drugs, increase insight into other inflammatory lung diseases, such as primary graft dysfunction in lung transplantation, and pave the way toward clinical translation.

1. Mehaffey JH, Charles EJ, Schubert S, Salmon M, Sharma AK, Money D, et al. In vivo lung perfusion rehabilitates sepsis-induced lung injury. J Thorac Cardiovasc Surg. 2018;155:440-8.

2. Carrel A, Lindbergh CA. The culture of whole organs. Science. 1935;81:621-3.

3. Cypel M, Yeung JC, Hirayama S, Rubacha M, Fischer S, Anraku M, et al. Technique for prolonged normothermic ex vivo lung perfusion. J Heart Lung Trans- 
4. Steen S, Sjöberg T, Pierre L, Liao Q, Eriksson L, Algotsson L. Transplantation of lungs from a non-heart-beating donor. Lancet. 2001;357:825-9.

5. Reck Dos Santos P, Sakamoto J, Chen M, Linacre V, Arce C, Liu M, et al. Modified in vivo lung perfusion for local chemotherapy: a preclinical study with doxorubicin. Ann Thorac Surg. 2016;101:2132-40.
6. Yeung JC, Wagnetz D, Cypel M, Rubacha M, Koike T, Chun YM, et al. Ex vivo adenoviral vector gene delivery results in decreased vector-associated inflammation pre- and post-lung transplantation in the pig. Mol Ther. 2012;20:1204-11.

7. Williams AE, Chambers RC. The mercurial nature of neutrophils: still an enigma in ARDS? Am J Physiol Lung Cell Mol Physiol. 2014;306:L217-30. 